ScIDice

\section{Assessment of Diabetic Status in Denture Stomatitis and Angular Cheilitis Patients in a University Hospital Setting - A Retrospective Analysis}

Lakshya Rani.S ${ }^{1}$, Sreedevi Dharman ${ }^{2 *}$, G.Maragathavalli ${ }^{3}$

${ }^{1}$ Saveetha Dental College and Hospitals, Saveetha Institute of Medical and Technical Sciences, Saveetha University, Chennai, India.

${ }^{2}$ Reader, Department of Oral Medicine and Radiology, Saveetha Dental College and Hospitals, Saveetha Institute of Medical and Technical Sciences, Saveetha University, Chennai, 600077, India.

${ }^{3}$ Professor, Department of Oral Medicine and Radiology, Saveetha Dental College and Hospitals, Saveetha Institute of Medical and Technical Sciences, Saveetha University, Chennai, 600077, India.

\title{
Abstract
}

Denture stomatitis and angular cheilitis is a form of oral candidiasis. It is a common opportunistic infection in diabetic patients. Presence of denture in the oral cavity of diabetic patients can increase the incidence of denture stomatitis and angular cheilitis. The aim of our study was to assess the diabetic status among the patients with denture stomatitis and angular cheilitis. This study is a Retrospective study conducted in a University hospital setting. The study population consists of 99 patients with denture stomatitis and angular cheilitis who had reported to the department of Oral Medicine and Radiology, Saveetha Dental College and Hospitals, Chennai, India. The data regarding the age, gender, diabetic status and clinical presentation of the patients were retrieved from patients records and analysed. The data with a total 86000 patients records between June2019 to March 2020 were taken and after fulfillment of inclusion and exclusion criteria, a final sample of 99 patients were considered.The data were tabulated and analysed by SPSS software and statistics done using Chi Square test with significance kept at $\mathrm{p}<0.05$. Prevalence of diabetic patients was found to be $15.1 \%$ among the study population. The prevalence of diabetic patients with Denture stomatitis was $11.1 \%$ and angular cheilitis was $4 \%$. Lesser number of patients with denture stomatitis and angular cheilitis were found to be diabetic Chi square $\mathrm{p}$ value- $0.095(\mathrm{p}>0.05)$. It was observed that prevalence of diabetic patients was found to be very less among the study population and no significant association was seen between diabetes and candida related lesions such as denture stomatitis and angular cheilitis.

Keywords: Denture Stomatitis; Angular Cheilitis; Oral Candidiasis; Diabetic.

\section{Introduction}

Diabetes mellitus is a common and growing global health problem which causes several complications. Diabetes has an increased predisposition to the manifestation of oral disease like candidiasis, denture stomatitis and angular cheilitis which are associated with poor glycemic control and therapeutic dentures [1]. This predisposition also contributes to xerostomia, which may be due to increased glucose levels. Wearing complete dentures is also known as a risk factor, which can promote Colonization of candida, produce candida biofilm and result in oral candidiasis [2]. Association of denture and diabetes can increase the incidence of oral candida disorders in diabetic patients $[1,3]$.

Diabetes mellitus is a chronic metabolic disease, which causes several disorders [2, 4]. Immunodeficiency and increased susceptibility to opportunistic infections are seen in diabetic patients. Colonization of candida is more prevalent in people with diabetes mellitus [1, 2]. Many studies have shown a higher prevalence of candidal colonization in the oral cavity of diabetes when compared to non-diabetic individuals [5, 6]. In addition, a significantly higher prevalence of oral candidiasis in people with diabetes is reported [7].

Candidal infection is found commonly in denture wearers [8].

\section{*Corresponding Author:}

Sreedevi Dharman,

Reader, Department of Oral Medicine and Radiology, Saveetha Dental College and Hospitals, Saveetha Institute of Medical and Technical Sciences, Saveetha University, Chennai, 600077, India.

Tel: +919841009003

E-mail: sreedevi@saveetha.com

Received: August 10, 2019

Accepted: August 28, 2019

Published: August 30, 2019

Citation: Lakshya Rani.S, Sreedevi Dharman, G.Maragathavalli. Assessment of Diabetic Status in Denture Stomatitis and Angular Cheilitis Patients in a University Hospital Setting - A Retrospective Analysis. Int J Dentistry Oral Sci. 2019;S4:02:008:36-41. doi: http://dx.doi.org/10.19070/2377-8075-SI02-04008

Copyright: Sreedevi Dharman ${ }^{\circ} 2019$. This is an open-access article distributed under the terms of the Creative Commons Attribution License, which permits unrestricted use, distribution and reproduction in any medium, provided the original author and source are credited. 
Acrylic dentures are an important predisposing factor for oral candidosis as these appliances, which are usually ill fitting with suboptimal hygiene, act as reservoirs of infection. It is also reported that high salivary yeast counts are much more common in complete denture wearers than indentate individuals [9] Commensal existence of intra oral candida species varies from $20 \%$ to $50 \%$ in a healthy edentulous population and up to $75 \%$ in denture-wearers [10]. The manifestation of oral candidiasis can occur in many different forms including median rhomboid glossitis, atrophic glossitis, denture stomatitis and angular cheilitis. Candidiasis is associated with a high density of yeasts in lesions [11].

Denture stomatitis is a term used to describe inflammatory changes in the oral mucosa of denture bearing tissues 11 . These changes are characterized by erythema and are found under complete or partial dentures in both jaws, but more frequently in the maxilla [12]. According to the clinical aspects of the lesions, Newton classified denture stomatitis as pinpoint hyperaemia (type I), diffuse erythematous hyperaemia (type II) and granular hyperaemia (type III) [13].

Angular cheilitis is the clinical diagnosis of deep fissures affecting the angles of the mouth and has an ulcerated appearance [14]. Etiological factors in relation to angular cheilitis are infection, low vertical vertical dimension, prolonged use of antibiotics, sensitivity to denture materials, vitamin deficiencies etc [15]. The aim of the study is to assess the diabetic status in denture stomatitis and angular cheilitis.

\section{Materials and Methods}

This study is a single- centred retrospective study, carried out in a private dental college. The present study was approved by Institutional ethical committee [IEC] (Ethical approval number: SDC/ SIHEC/2020/DIASDATA/0619-0320) and was in accordance with the ethical standards that were stipulated. All available records of patients from June 2019 - April 2020 were examined and a total of 86000 case sheets were reviewed. Patients above 18 years and those with candida related lesions such as denture stomatitis and angular cheilitis were included in the study. Those who visited outside the time frame, with other candida associated lesions were excluded from the study. Cross verification of data for error was done by presence of additional reviewers and by photographs evaluation. Two examiners were involved in the study. Any patient with incomplete data was excluded from the study.

\section{Data collection}

Acquisition of data was done from the hospital database which records all patient details. The study included 99 patients with denture stomatitis and angular cheilitis. The collected data were grouped based on denture stomatitis and angular cheilitis .Age was categorised into 18 - 35 years, 36- 55 years and older than 55 years. Gender was categorised into males and females. The medical history of the patients with denture stomatitis and angular cheilitis were verified to assess the diabetic status in the study population. The data were entered in the system in a methodical manner. For this study, data regarding age, gender and diabetic status of the patients were collected. The data was then entered in excel manually and imported to SPSS for analysis. Incomplete or censored data were excluded from the study.

\section{Statistical analysis}

The statistical analysis was done using SPSS software (SPSS version 21.0, SPSS, Chicago II, USA). Descriptive statistics was used to summarise the demographic information of the patients included in this study. Descriptive statistics is used for the acquisition of frequency distribution of the data. Chi-square test was applied to analyse the association of different variables. Statistical significance was kept at $\mathrm{p}<0.05$.

\section{Results and Discussion}

The study population consists of 99 patients above 18 years of age. Based on the distribution of study population by age, $15.1 \%$ of the patients were found within the age group of 18 - 35 years, $43.4 \%$ of the patients were found in the age group of $35-55$ years and $41.4 \%$ of the patients were found over 55 years of age Figure 1). Based on the distribution of population by gender, $47.4 \%$ of the patients were found to be males and $52.5 \%$ of the patients were found to be females (Figure 2). Based on the diabetic status of the patients, $15.1 \%$ of the patients were found to be diabetic and $84.1 \%$ of the patients were found to be non- diabetic

Figure 1. Bar chart represents frequency of age distribution among patients with denture stomatitis and angular cheilitis. $\mathrm{X}$ axis denotes the age group of the patients and $\mathrm{Y}$ axis denotes the number of patients with denture stomatitis and angular cheilitis. Patients with denture stomatitis and angular cheilitis were seen more in the age group of 36-55years (43.4\%) when compared to other age groups.

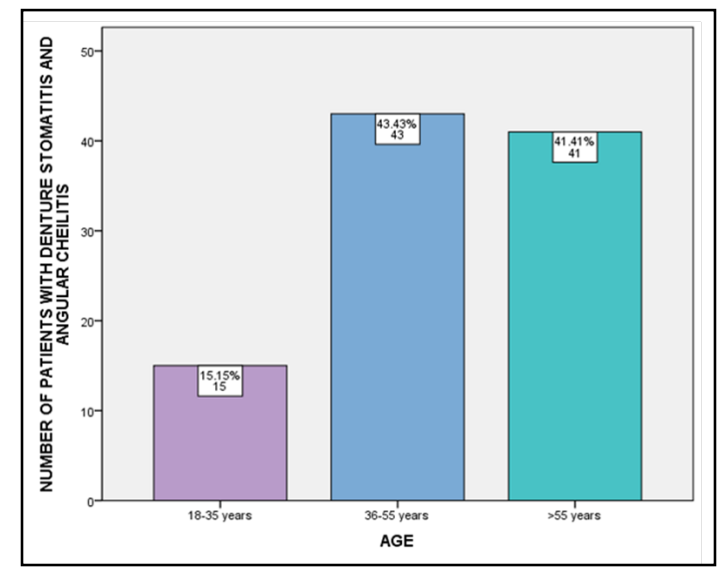


(Figure 3). Based on the prevalence of types of denture stomatitis among diabetic patients, $54.5 \%$ of the diabetics patients were found to present with Type II denture stomatitis and $45.4 \%$ of the diabetic patients were found to present with Type I denture stomatitis (Figure 4).

Based on the association of age group, denture stomatitis and angular cheilitis, $4 \%$ of the patients with denture stomatitis and $11.1 \%$ of the patients with angular cheilitis were found within the age group of 18 - 35 years; $22.2 \%$ of the patients with denture stomatitis and $21.1 \%$ of the patients with angular cheilitis were found within the age group of 35 - 55 years; $28.2 \%$ of the patients with denture stomatitis and $13.1 \%$ of the patients with angular cheilitis were found over 55 years of age, $p$ value- $0.255(p<0.05)$, statistically not significant (Figure 5). Association of gender and candida related lesion showed $23.2 \%$ of the patients with denture stomatitis and $24.2 \%$ of the patients with angular cheilitis were found to be males; $31.3 \%$ of the patients with denture stomatitis and $21.2 \%$ of the patients with angular cheilitis were found to be females, $\mathrm{p}$ value -0.585 ( $\mathrm{P}>0.05$ ), statistically not significant (Figure 6).

Association of age and diabetic status of the study population showed $1 \%$ of the patients with diabetes and $14.1 \%$ of the patients without diabetes were found within the age group of 18- 35 years; $5 \%$ of the patients with diabetes and $38.3 \%$ of the patients without diabetes were found within the age group of $35-55$ years; $9 \%$ of the patients with diabetes and $32.2 \%$ of the patients without diabetes were found over 55 years of age, $\mathrm{p}$ value -0.245 $(\mathrm{P}>0.05)$ statistically not significant (Figure 7 ). $7 \%$ of the patients with diabetes and $40.4 \%$ of the patients without diabetes were found to be males; $8 \%$ of the patients with diabetes and $44.4 \%$ of the patients without diabetes were found to be females, $\mathrm{p}$ value $-0.585(\mathrm{P}>0.05)$ (Figure 8$)$. Association of diabetic status with denture stomatitis and angular cheilitis, $11.1 \%$ of the patients with denture stomatitis and $4 \%$ of the patients with angular cheilitis were found to be diabetic; $43.4 \%$ of the patients with denture stomatitis and $41.4 \%$ of the patients with angular cheilitis were found to be non-diabetic, p value - 0.095 ( $\mathrm{P}>0.05)$ statistically not significant (Figure 9).

Dorocka et al observed that $57.3 \%$ of diabetic patients had type II denture stomatitis [16]. This is similar to the results of our current study where $54.5 \%$ of diabetic patients had type II denture stomatitis. In a study of 463 randomly selected geriatric denture wearers, the prevalence of denture stomatitis was to be high as $65 \%$ [17] and these lesions are seen more frequently among women than men, which is in accordance with our study were denture stomatitis was more common in females. Axell et al says that prevalence of angular cheilitis is more frequently seen in

Figure 2. Bar chart represents the frequency of gender variation among patients with denture stomatitis and angular cheilitis. $\mathrm{X}$ axis denotes the gender of the patients and $\mathrm{Y}$ axis denotes the number of patients with denture stomatitis and angular cheilitis. Majority of patients with denture stomatitis and angular cheilitis were found to be females (52.5\%) when compared to males $(47.4 \%)$.

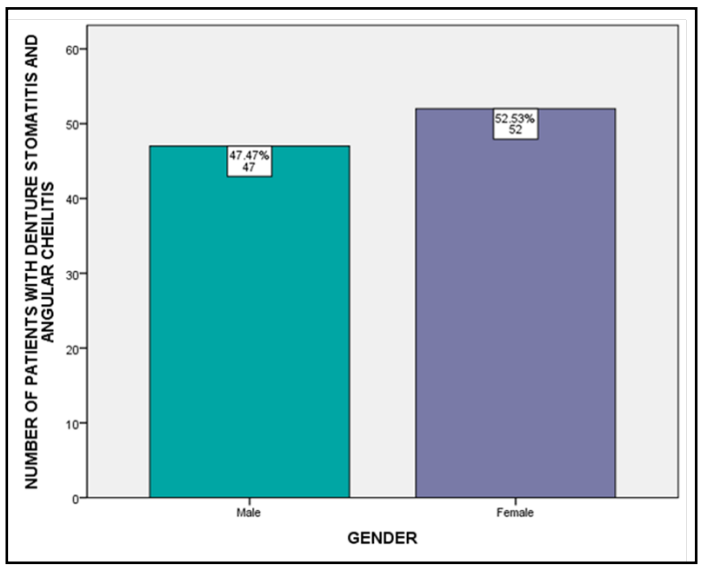

Figure 3. Bar chart represents the diabetic status of the patients with denture stomatitis and angular cheilitis. $\mathrm{X}$ axis denotes the diabetic status and the $\mathrm{Y}$ axis denotes the number of patients with denture stomatitis and angular cheilitis. Lesser number of patients with denture stomatitis and angular cheilitis were found to be diabetic (15.1\%).

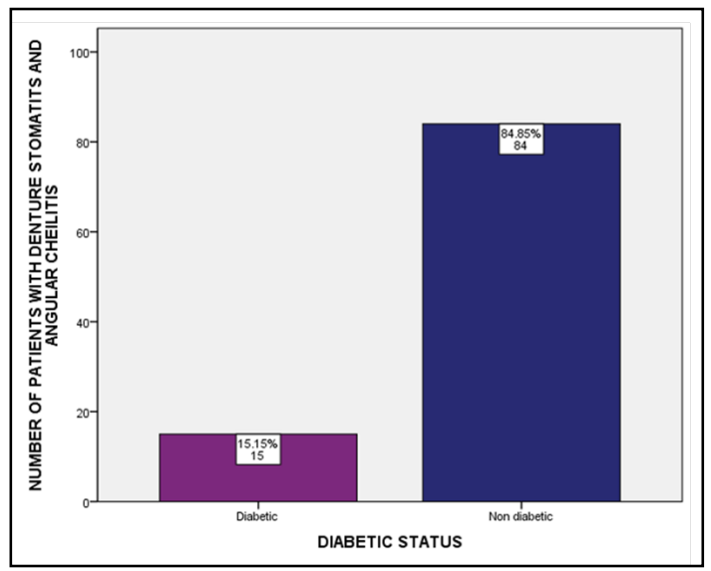


Figure 4. Bar chart represents the types of denture stomatitis in diabetic patients. $\mathrm{X}$ axis denotes the types of denture stomatitis and $\mathrm{Y}$ axis denotes the number of diabetic patients with denture stomatitis. Majority of the diabetic patients were found to present with Type II denture stomatitis (54.5\%).

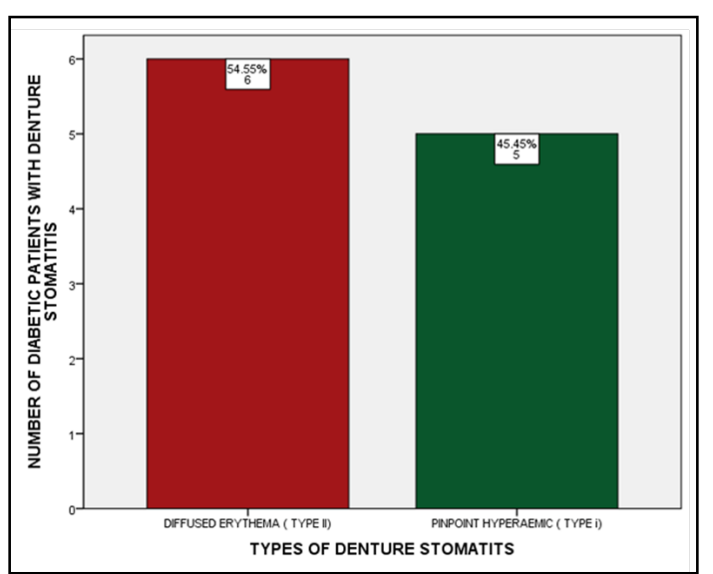

Figure 5. Bar chart represents the association between age and patients with denture stomatitis and angular cheilitis. $\mathrm{X}$ axis denotes age group of patients and $\mathrm{Y}$ axis denotes number of patients with denture stomatitis and angular cheilitis. Majority of the patients with denture stomatitis were over 55 years of age and patients with angular cheilitis were in $35-55$ years. Chi square analysis done, $p$ value $-0.255(P>0.05)$, statistically not significant.

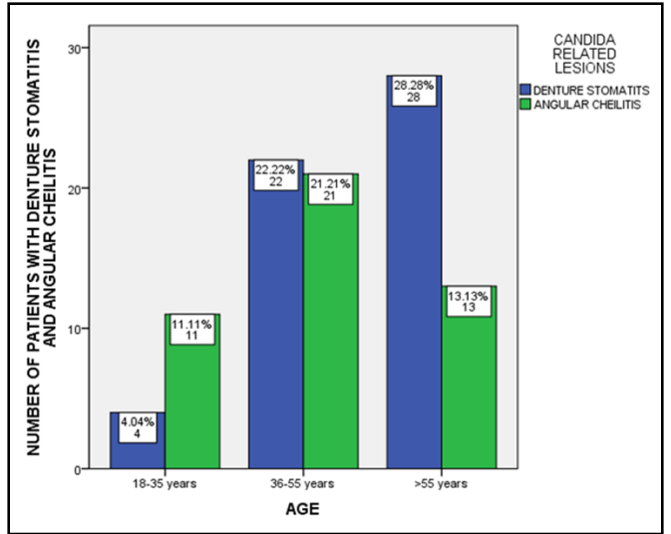

Figure 6. Bar chart represents the association between gender and patients with denture stomatitis and angular cheilitis. $\mathrm{X}$ axis denotes the gender of the patients and the $\mathrm{Y}$ axis denotes the number of patients with denture stomatitis and angular cheilitis. Majority of the patients with denture stomatitis were found to be females and patients with angular cheilitis were found to be males. Chi square $p$ value -0.585 ( $P>0.05)$, statistically not significant.

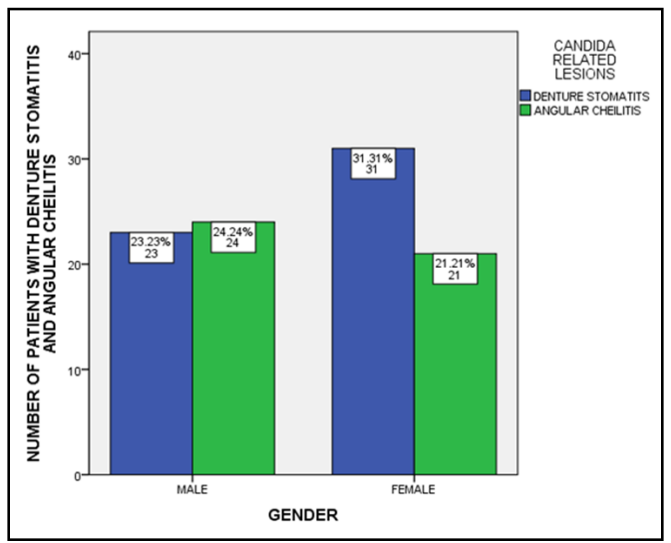

women than in men [18] which is in contrast to our study where angular cheilitis is more common in males. The prevalence of angular cheilitis among complete dentures wearers has been shown to vary between 8 and 30\% [19,16]. Rahmi et al., observed that prevalence of diabetes is high $(65 \%)$ in the patients with angular cheilitis [20]. However, this is not similar to our result where only $4 \%$ of the diabetic patients had angular cheilitis. In a study conducted by Makila et al., it was observed that, in diabetic patients the prevalence of denture stomatitis was found to be as high as $75 \%$ [21], which does not support our result where only $11.1 \%$ of the patients were found with denture stomatitis. Literature says, people with type 11 diabetes mellitus stand a higher risk of developing denture stomatitis than the non-diabetics [22].
In a study, the prevalence of denture stomatitis was found to be significantly higher in diabetic patients than in control subjects $(\mathrm{P}=0.018)$ [23]. A literature search revealed conflicting reports about the association of denture stomatitis with diabetes mellitus [24]. A study reported that the prevalence of angular cheilitis was found to be significantly higher in diabetic patients than in control subjects $(\mathrm{P}<0.05)$ [25], but our study results are contrary to the previous literature. It is generally acknowledged that diabetic patients are more susceptible to fungal infections, particularly to Candida albicans infections, than non-diabetic subjects [26]. Hyperglycemia due to poor metabolic control is one possible predisposing factor of oral candidiasis in diabetic patients. This can lead 
Figure 7. Bar chart represents the association between age and diabetic status of the patients with denture stomatitis and angular cheilitis. $\mathrm{X}$ axis denotes the age group of the patients and the $\mathrm{Y}$ axis denotes the number of patients with denture stomatitis and angular cheilitis. Majority of the patients were found to be diabetic over 55 years of age. Chi square $p$ value 0.245 ( $P>0.05)$. hence, statistically not significant.

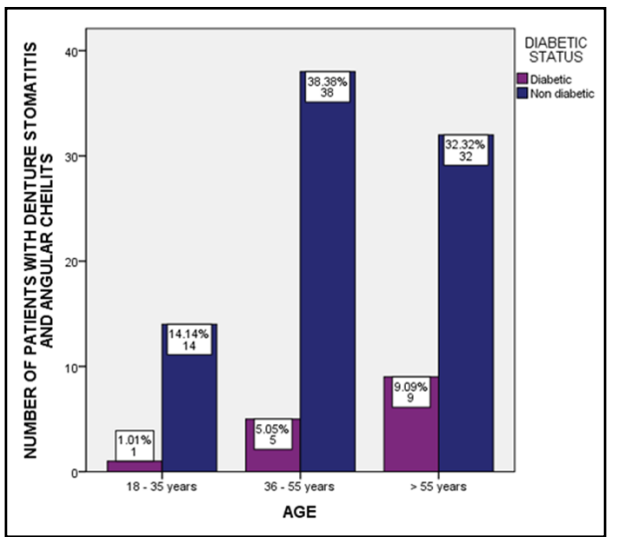

Figure 8. Bar chart represents the association between gender and diabetic status of the patients with denture stomatitis and angular cheilitis. $\mathrm{X}$ axis denotes the gender of the patients and the $\mathrm{Y}$ axis denotes the number of patients with denture stomatitis and angular cheilitis. Majority of the patients without diabetes were seen in females when compared to males.

Chi square $p$ value -0.585 ( $P>0.05)$, statistically not significant.

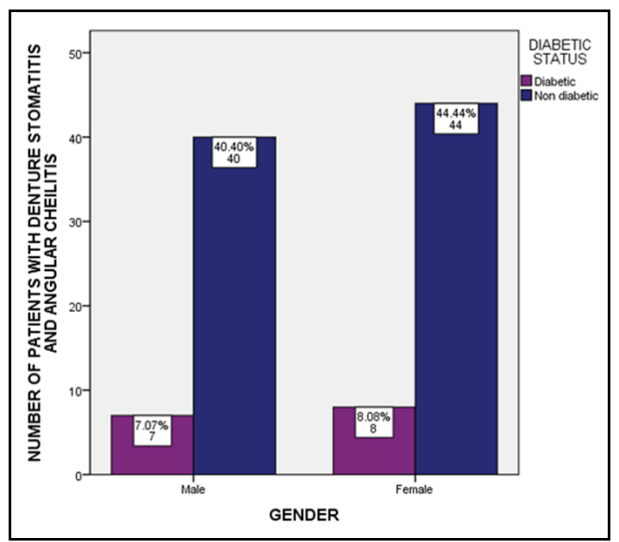

Figure 9. Bar chart represents the association between diabetic status and patients with denture stomatitis and angular cheilitis. $\mathrm{X}$ axis denotes the diabetic status of the patients and $\mathrm{Y}$ axis denotes the number of patients with candida related lesions. Lesser number of patients with denture stomatitis and angular cheilitis were found to be diabetic. Chi square $p$ value - 0.095 ( $P>0.05)$, statistically not significant.

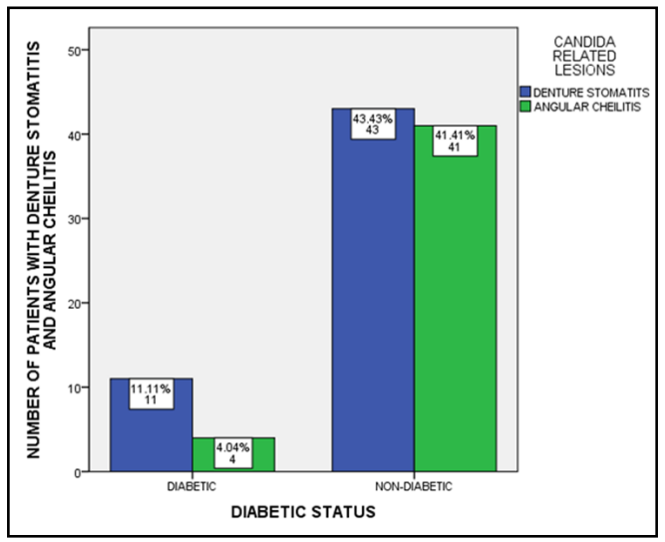

to the growth of Candida albicans and enhanced adhesiveness to the oral epithelium 21 in association with other local factors such as the presence of dental prostheses, salivary $\mathrm{pH}$, salivary flow rate, and oral habits [26].

Thus, the current study is not in accordance with the previous literature, this evidence adds to the consensus and can be used in diagnosis in a clinical practice. Previously our team had conducted numerous clinical trials [27-31] and lab studies [32-36] and in vitro studies [37-41] over the past 5 years. The limitations of the study could be smaller sample size. However, for better results and significance, cohort study can be done to assess the diabetic status among the patients with denture stomatitis and angular cheilitis on a larger sample size. 


\section{Conclusion}

Within the limits of the study it was observed that, $15.1 \%$ of the patients with denture stomatitis and angular cheilitis were diabetic. Type II denture stomatitis were more common in diabetic patients.There was no significant association of diabetic status with denture stomatitis and angular cheilitis patients. However, glycemic levels should be monitored regularly in patients with diabetes to prevent candida associated lesions.

\section{Acknowledgement}

This research was supported by Saveetha Dental College and Hospital. We thank the department of Oral Medicine and Radiology, Saveetha Dental College for providing insight and expertise that greatly assisted this research.

\section{References}

[1]. Lotfi-Kamran MH, Jafari AA, Falah-Tafti A, Tavakoli E, Falahzadeh MH. Candida Colonization on the Denture of Diabetic and Non-diabetic Patients. Dent Res J (Isfahan). 2009 Spring;6(1):23-7.Pubmed PMID: 21528026.

[2]. Barbeau J, Séguin J, Goulet JP, de Koninck L, Avon SL, Lalonde B, et al. Deslauriers N. Reassessing the presence of Candida albicans in denture-related stomatitis. Oral Surg Oral Med Oral Pathol Oral Radiol Endod. 2003 Jan;95(1):51-9.Pubmed PMID: 12539027.

[3]. Soell M, Hassan M, Miliauskaite A, Haikel Y, Selimovic D. The oral cavity of elderly patients in diabetes. Diabetes Metab. 2007 Apr 1;33:S10-8.

[4]. Sahin I, Oksuz S, Sencan I, Gulcan A, Karabay O, Gulcan E, et al. Prevalance and risk factors for yeast colonization in adult diabetic patients. Ethiop Med J. 2005 Apr;43(2):103-9.

[5]. Kumar BV, Padshetty NS, Bai KY, Rao MS. Prevalence of Candida in the oral cavity of diabetic subjects. J Assoc Physicians India. 2005 Jul;53:599.

[6]. Geerlings SE, Hoepelman AI. Immune dysfunction in patients with diabetes mellitus (DM). FEMS Immunol Med Microbiol. 1999 Dec 1;26(3-4):25965.

[7]. Webb BC, Thomas CJ, Willcox MD, Harty DW, Knox KW. Candida-associated denture stomatitis. Aetiology and management: A review: Part1. Factors influencing distribution of candida species in the oral cavity. Aust. Dent. J.. 1998 Feb;43(1):45-50.

[8]. Bergendal T. Status and treatment of denture stomatitis patients: a 1-year follow-up study. Scand J Dent Res. 1982 Jun;90(3):227-38.Pubmed PMID: 6955935.

[9]. Al-Maskari AY, Al-Maskari MY, Al-Sudairy S. Oral manifestations and complications of diabetes mellitus: a review. Sultan Qaboos Univ Med J. 2011 May;11(2):179.

[10]. Emami E, de Grandmont P, Rompré PH, Barbeau J, Pan S, Feine JS. Favoring trauma as an etiological factor in denture stomatitis. J Dent Res. 2008 May;87(5):440-4.Pubmed PMID: 18434573.

[11]. Miller EL. Denture induced inflammations. The Journal of the Dental Association of South Africa= Die Tydskrif van die Tandheelkundige Vereniging van Suid-Afrika 1975; 30: 89.

[12]. Golecka M, Ołdakowska-Jedynak U, Mierzwińska-Nastalska E, AdamczykSosińska E. Candida-associated denture stomatitis in patients after immunosuppression therapy. Transplant Proc. 2006 Jan-Feb;38(1):155-6.Pubmed PMID: 16504690

[13]. Sharma, Sharma, Dheeraj, et al. The Tale of Two Professors. Epub ahead of print 2015. DOI: $10.4135 / 9781526429575$.

[14]. Lorenzo-Pouso AI, García-García A, Pérez-Sayáns M. Hyaluronic acid dermal fillers in the management of recurrent angular cheilitis: A case report. Gerodontology. 2018 Jun;35(2):151-154.Pubmed PMID: 29733533.

[15]. Oza N, Doshi JJ. Angular cheilitis: A clinical and microbial study. Indian J. Dent. Res. 2017 Nov 1;28(6):661-665.

[16]. Dorocka-Bobkowska B, Zozulinska-Ziolkiewicz D, Wierusz-Wysocka B, Hedzelek W, Szumala-Kakol A, Budtz-Jörgensen E. Candida-associated denture stomatitis in type 2 diabetes mellitus. Diabetes Res Clin Pract. 2010 Oct;90(1):81-6.Pubmed PMID: 20638146.

[17]. Geerts GA, Stuhlinger ME, Basson NJ. Effect of an antifungal denture liner on the saliva yeast count in patients with denture stomatitis: a pilot study. J Oral Rehabil. 2008 Sep;35(9):664-9.Pubmed PMID: 18793352.

[18]. Axéll T. A prevalence study of oral mucosal lesions in an adult Swedish population. Odontol Revy Suppl. 1976;36:1-103.Pubmed PMID: 186740.

[19]. Turker SB, Sener ID, Koçak A, Yilmaz S, Ozkan YK. Factors triggering the oral mucosal lesions by complete dentures. Arch Gerontol Geriatr. $2010 \mathrm{Jul}-$ Aug;51(1):100-4.Pubmed PMID: 19819567.

[20]. Sharmila R, Muralidharan NP. Angular Chelitis in Complete Dentures. J. Pharm. Sci. Res. 2015 Aug 1;7(8):598.

[21]. Darwazeh AM, Lamey PJ, Samaranayake LP, MacFarlane TW, Fisher BM, Macrury SM, et al. The relationship between colonisation, secretor status and in-vitro adhesion of Candida albicans to buccal epithelial cells from diabetics. J Med Microbiol. 1990 Sep;33(1):43-9.Pubmed PMID: 2231671.

[22]. Quinterol OM, Borrego AP, Fernández YF. Influence of Diabetes Mellitus on the oral health of the elderly. MOJ Gerontol Ger. 2017;2(3):241-4.

[23]. Al-Maweri SA, Ismail NM, Ismail AR, Al-Ghashm A. Prevalence of oral mucosal lesions in patients with type 2 diabetes attending hospital universiti sains malaysia. Malays J Med Sci. 2013 Jul;20(4):39-46.Pubmed PMID: 24043995.

[24]. Phelan JA, Levin SM. A prevalence study of denture stomatitis in subjects with diabetes mellitus or elevated plasma glucose levels. Oral Surg Oral Med Oral Pathol. 1986 Sep 1;62(3):303-5.

[25]. Ali M, Joseph B, Sundaram D. Prevalence of oral mucosal lesions in patients of the Kuwait University Dental Center. Saudi Dent J. 2013 Jul;25(3):1118.Pubmed PMID: 24179320.

[26]. Vazquez JA, Sobel JD. Fungal infections in diabetes. Infect Dis Clin North Am. 1995 Mar;9(1):97.

[27]. Venugopal A, Uma Maheswari TN. Expression of matrix metalloproteinase-9 in oral potentially malignant disorders: A systematic review. J Oral Maxillofac Pathol. 2016 Sep-Dec;20(3):474-479.Pubmed PMID: 27721614

[28]. Chaitanya NC, Muthukrishnan A, Babu DBG, Kumari CS, Lakshmi MA, Palat G, et al. Role of Vitamin E and Vitamin A in Oral Mucositis Induced by Cancer Chemo/Radiotherapy- A Meta-analysis. J Clin Diagn Res. 2017 May;11(5):ZE06-ZE09.Pubmed PMID: 28658926.

[29]. Subashri A, Maheshwari TN. Knowledge and attitude of oral hygiene practice among dental students. Res J Pharm Technol. 2016;9(11):1840-2.

[30]. Maheswari TNU, Venugopal A, Sureshbabu NM, Ramani P. Salivary micro RNA as a potential biomarker in oral potentially malignant disorders: A systematic review. Ci Ji Yi Xue Za Zhi. 2018 Apr-Jun;30(2):55-60.Pubmed PMID: 29875583.

[31]. Misra SR, Shankar YU, Rastogi V, Maragathavalli G. Metastatic hepatocellular carcinoma in the maxilla and mandible, an extremely rare presentation. Contemp Clin Dent. 2015 Mar;6(Suppl 1):S117-21.Pubmed PMID: 25821363.

[32]. Steele JC, Clark HJ, Hong CH, Jurge S, Muthukrishnan A, Kerr AR, et al. World Workshop on Oral Medicine VI: an international validation study of clinical competencies for advanced training in oral medicine. Oral Surg Oral Med Oral Pathol Oral Radiol. 2015 Aug;120(2):143-51.e7.Pubmed PMID: 25861956.

[33]. Chellammal MR, Dharman S. Assessment of Enamel Defects in Patients Visiting Saveetha Dental College, Chennai: A Pilot Study. Res J Pharm Biol Chem Sci. 2016 May 1;7(3):995-1001.

[34]. Muthukrishnan A, Warnakulasuriya S. Oral health consequences of smokeless tobacco use. Indian J Med Res. 2018 Jul;148(1):35.

[35]. Chaitanya NC, Muthukrishnan A, Krishnaprasad CMS, Sanjuprasanna G, Pillay P, Mounika B. An Insight and Update on the Analgesic Properties of Vitamin C. J Pharm Bioallied Sci. 2018 Jul-Sep;10(3):119-125.Pubmed PMID: 30237682

[36]. Rohini S, Kumar VJ. Incidence of dental caries and pericoronitis associated with impacted mandibular third molar-A radiographic study. Res J Pharm Technol. 2017;10(4):1081-4.

[37]. Dharman S, Muthukrishnan A. Oral mucous membrane pemphigoid - Two case reports with varied clinical presentation. J Indian Soc Periodontol. 2016 Nov-Dec;20(6):630-634.Pubmed PMID: 29238145.

[38]. Subha M, Arvind M. Role of magnetic resonance imaging in evaluation of trigeminal neuralgia with its anatomical correlation. Biomed. Pharmacol. J. 2019 Mar 25;12(1):289-96.

[39]. Muthukrishnan A, Bijai Kumar L. Actinic cheilosis: early intervention prevents malignant transformation. BMJ Case Rep. 2017 Mar 20;2017:bcr2016218654.Pubmed PMID: 28320702.

[40]. Umamaheswari TN. Salivary biomarkers in oral leukoplakia-a review. Int J Pharm Bio Sci. 2014;6(5):3014-8.

[41]. Muthukrishnan A, Bijai Kumar L, Ramalingam G. Medication-related osteonecrosis of the jaw: a dentist's nightmare. BMJ Case Rep. 2016 Apr 6;2016:bcr2016214626.Pubmed PMID: 27053542 